\title{
LAND SUBSIDENCE HAZARD IN IRAN REVEALED BY COUNTRY-SCALE ANALYSIS OF SENTINEL-1 INSAR
}

\author{
M. Haghshenas Haghighi ${ }^{1 *}$, M. Motagh ${ }^{1,2}$ \\ ${ }^{1}$ Institute of Photogrammetry and GeoInformation, Leibniz University Hannover, Germany - mahmud@ipi.uni-hannover.de \\ ${ }^{2}$ GFZ German Research Centre for Geosciences, Potsdam, Germany - motagh@gfz-potsdam.de
}

KEY WORDS: Land subsidence, InSAR, Time series analysis, Hazard, Big data.

\begin{abstract}
:
Many areas across Iran are subject to land subsidence, a sign of exceeding stress due to the over-extraction of groundwater during the past decades. This paper uses a huge dataset of Sentinel-1, acquired since 2014 in 66 image frames of $250 \times 250 \mathrm{~km}$, to identify and monitor land subsidence across Iran. Using a two-step time series analysis, we first identify subsidence zones at a medium scale of $100 \mathrm{~m}$ across the country. For the first time, our results provide a comprehensive nationwide map of subsidence in Iran and recognize its spatial distribution and magnitude. Then, in the second step of analysis, we quantify the deformation time series at the highest possible resolution to study its impact on civil infrastructure. The results spots the hazard posed by land subsidence to different infrastructure. Examples of road and railways affected by land subsidence hazard in Tehran and Mashhad, two of the most populated cities in Iran, are presented in this study.
\end{abstract}

\section{INTRODUCTION}

The scarcity of water resources in many areas of the world has made communities dependent on groundwater pumping for municipal, industrial, and agricultural purposes. As a result, many aquifers around the globe are subject to exceeding stress (Wada et al., 2011, Ashraf et al., 2017, Alley et al., 2018). Global freshwater modeling and satellite gravity measurements of GRACE confirm that this is a worldwide issue (Alcamo et al., 2003, Richey et al., 2015). However, at national or basins scales, quantifying groundwater stress is more challenging mainly because groundwater is not directly accessible.

Land subsidence associated with groundwater extraction is a sign of water stress. It can be measured, without direct access to groundwater, by using different geodetic techniques such as leveling or Global Navigation Satellite System (GNSS) measurements (Mousavi et al., 2001, Wang and Soler, 2015). In recent decades, Interferometric Synthetic Aperture Radar (InSAR) has been widely used to map land subsidence at many aquifers around the world (Amelung et al., 1999, Chaussard et al., 2014, Castellazzi et al., 2016). Measurement of land subsidence not only indicates regional stress on the aquifer systems due to groundwater extraction, but it also provides information to assess present and the future hazard posed to the infrastructures and properties (Galloway and Burbey, 2011, Cigna et al., 2012).

Located in an arid to semi-arid region, Iran is one of the highest affected areas by groundwater stress (Madani et al., 2016). All sectors in Iran are dependent on groundwater, but agriculture alone is responsible for approximately $90 \%$ of groundwater consumption. The country is only second to India in groundwater depletion embedded in food production (Dalin et al., 2017). Land subsidence attributed to the over-extraction of groundwater is a widespread problem in many developed basins across Iran. It has affected agricultural and urban areas and threatened civil infrastructures such as roads, bridges, and railways in many parts.

\footnotetext{
* Corresponding author
}

Although land subsidence is a significant concern, from the water management and hazard control aspects, a complete database of affected areas and their dynamics in response to regional changes in groundwater depletion is not available yet. Previous studies indicated land subsidence in some of the most critical areas of the country. For example, Tehran, Iran's capital, and Rafsanjan, Iran's center of Pistachio plantation, have been experiencing land subsidence of up to $25 \mathrm{~cm} / \mathrm{yr}$ (Motagh et al., 2008, Motagh et al., 2017, Haghshenas Haghighi and Motagh, 2019). The previous studies on land subsidence in Iran were conducted in relatively small areas, i.e., at local to regional scales (Mousavi et al., 2001, Motagh et al., 2007, Dehghani et al., 2009, Babaee et al., 2020).

The launch of the Sentinel-1 mission in 2014 provided an avalanche of publicly available SAR data suitable for InSAR analysis of surface deformation. This mission acquires data regularly from the same orbit every 6 or 12 days. Overland, it covers an extensive swath of $250 \mathrm{~km}$ and acquires SAR images with $20 \times 5 \mathrm{~m}$ resolution in azimuth and range directions, respectively. Using two SAR images from the same orbit, it is possible to generate an interferogram and measure a snapshot of surface deformation e.g., caused by land subsidence.

Using more images, it is possible to analyze the time series of deformation. In the past two decades, several advanced methods including SqueeSAR (Ferretti et al., 2011) Persistent Scatterer (PS) (Hooper et al., 2007) and Small BAseline Subset (SBAS) (Hooper, 2008) have been developed for InSAR time series analysis. All these methods follow a few general steps. First, they generate a stack of interferograms from the SAR images. They, they identify pixels that preserve quality in the stack of interferograms. In the next step, they connect the interferometric phase of interferograms in the time domain to produce a time series. Finally, they estimate and reduce the errors, such as atmospheric phase delay, to produce the displacement time series.

In this study, we perform InSAR measurements on a large stack of SAR data acquired by Copernicus Sentinel-1 mission to de- 
tect and monitor, for the first time, the magnitude of land subsidence and the exact extent of affected areas across Iran. We perform Interferometric analysis at two different scales: first, we identify the subsidence areas at a medium resolution of 100 $\mathrm{m}$. Then, we analyze the time series of subsidence at the specified locations at the highest possible resolution.

In the next section, we introduce the dataset and methods used to investigate land subsidence in Iran. In the results, we first introduce the nationwide subsidence map of Iran and discuss its highlights. Then, we show two examples of InSAR time series analysis at high resolution for infrastructure monitoring in Tehran and Mashhad, the two most populated cities in Iran.

\section{DATA AND METHOD}

We use 66 image frames, each covering a $250 \times 250-\mathrm{km}$ area, in 11 descending tracks acquired by Sentinel-1 mission. Although land subsidence is a dynamic phenomenon, the nationwide picture of land subsidence is not expected to change over a few years. Therefore, we employ more than 3500 SAR images acquired throughout three years between 2014 and 2017 to identify subsidence areas. Then, we use the entire archive of Sentinel-1 data to perform monitoring of subsidence for the identified areas. Figure 1 shows the frames of Sentinel-1 covering the whole country of Iran, which is as large as approximately 1.6 million $\mathrm{km}^{2}$. Using this large dataset, we can identify the subsidence hotspots across the country and analyze their time series of displacement.

Analyzing such a large SAR dataset using advanced time series methods at the highest possible resolution needs a high computational resource. Such resources can be provided, for example, by cloud processing environments or High Performance Computing (HPC) systems. Despite that, our study aims at reducing the computational barrier and therefore, we implement a multiscale approach illustrated in Figure 2.

In this approach, we implement a pre-processing followed by the identification and monitoring steps. In the pre-processing

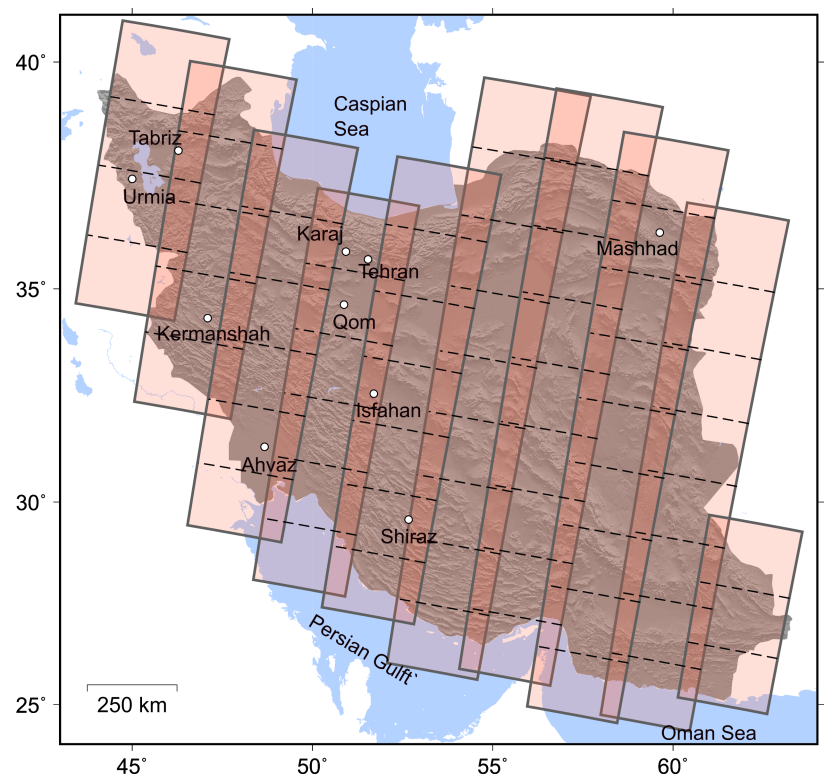

Figure 1. Coverage of Sentinel-1 frames in descending path in Iran overlaid on a shaded-relief map. Small circles indicate ten most populous cities of the country.

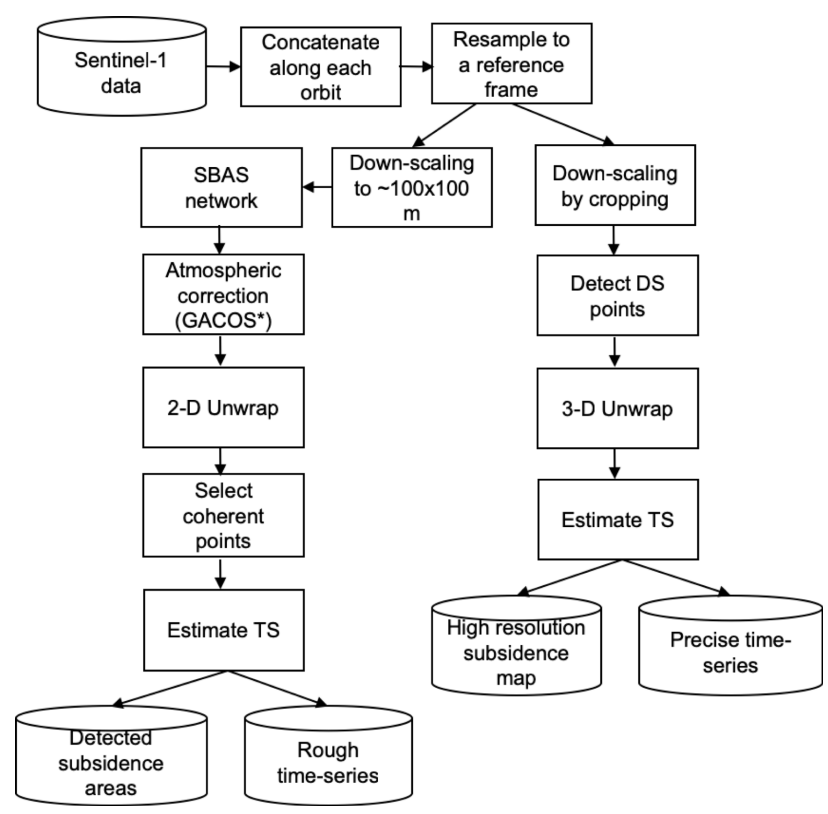

Figure 2. Flowchart of our multi-scale approach to detect and monitor land subsidence using large stacks of Sentinel-1 data.

stage, we concatenate all SAR data along each acquisition track. In each track, after selecting one image as a reference, we coregister and resample all other images. The coregistration should be performed accurately to prevent any jump between Sentinel1 TOPS bursts (Yagüe-Martínez et al., 2016). After producing a pool of resampled images, ready for interferogram generation, we split the processing chain into two main steps. During this two steps, we first identify the subsidence zones using a limited amount of data, and then monitor them using the full archive of data at highest possible resolution.

In the first step of our processing chain, we detect subsidence areas by analyzing the data at a large spatial extent but a medium spatial resolution. To do so, we process each track of data individually using Small Baseline Subset (SBAS) time series analysis (Berardino et al., 2002). Here, we use a spatial resolution of approximately $100 \mathrm{~m}$ which corresponds to interferogram multi-looking of $25 \times 5$ in range and azimuth, respectively. The tropospheric phase is removed from the interferograms using SRTM 3 arc-sec DEM (Farr and Kobrick, 2000). The atmospheric artifact is corrected using external data from Generic Atmospheric Correction Online Service for InSAR (GACOS) (Yu et al., 2018). The corrected interferograms are then unwrapped in two dimensions in space. We use a coherence threshold of 0.2 in $75 \%$ of the interferograms to drop pixels with a low signal-to-noise ratio. For the pixels with higher coherence, we estimate the deformation rate and time series of displacement. Using the average rate of displacement obtained from SBAS analysis, we identify subsidence zones across the country.

After detecting the subsidence zones, for each area of interest, the data is down-scaled by cropping, and a precise time series analysis is performed at the highest possible resolution as described in (Hooper, 2008). In this way, a high-resolution subsidence map and a precise time series of displacement are estimated for every specific area. Assuming the deformation is mainly driven by land subsidence, we neglect the horizontal components of displacement and convert the line of sight deformation $\left(u_{l o s}\right)$ into vertical $\left(u_{v}\right)$ by $u_{v}=u_{l o s} / \cos (\theta)$ where 
$\theta$ is the incidence angle of each pixel.

\section{RESULTS}

In this section, we discuss the results of the InSAR analysis of land subsidence in Iran. First, we show the nationwide subsidence map of Iran, using which we identify subsidence zones. Then, we offer examples of high-resolution InSAR time series analysis in two subsidence zones.

\subsection{Nation-wide identification of subsidence zones}

Figure 3 shows the linear rate of displacement across Iran estimated from InSAR time series analysis of Sentinel-1 data down scaled to $100 \times 100 \mathrm{~m}$. Except for two narrow bands in the north and west of the country, where Alborz and Zagros mountain ranges are located, and two desert areas in the country's central and eastern parts, land subsidence affects most of Iran's populated areas. We identified more than 100 subsidence zones with subsidence rates greater than $2 \mathrm{~cm} /$ year across the country. In general, land subsidence in different regions is strongly co-located with farming areas. It confirms that, to a large extent, pumping water for irrigation is responsible for groundwater stress.

The subsidence map indicates that land subsidence is widespread across the country, with several hotspots in different regions, four of which are illustrated in Figure 4. One of the most prominent hotspots is located to the southern feet of the Alborz mountains, where more than a quarter of the countries population lives. The maximum rate of subsidence in this area reaches approximately $30 \mathrm{~cm} /$ year to the west of Karaj. In the subsidence zone to the southwest of Tehran, the subsidence exceeds $16 \mathrm{~cm} /$ year.

The second subsidence hotspot is located in the northeastern province of Khorasan-Razavi, which is second in the country's

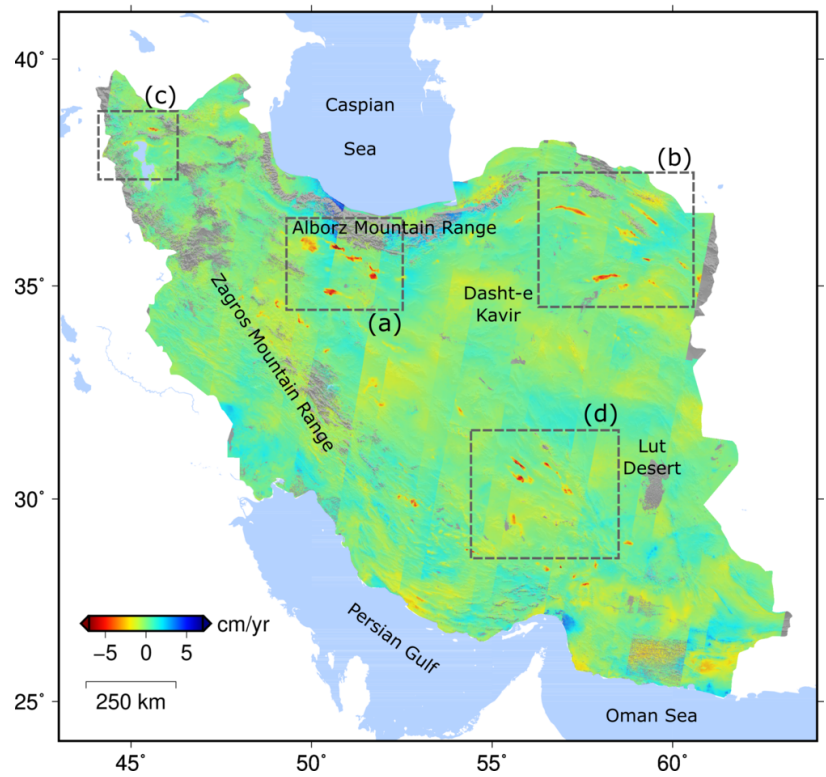

Figure 3. The linear rate of displacement across Iran obtained from Sentinel-1 time series analysis at a medium resolution of $100 \mathrm{~m}$. The color scale is saturated between \pm 7 to highlight small subsidence areas. Four subsidence hot spots indicated by dashed lines are shown in details in figure 4.
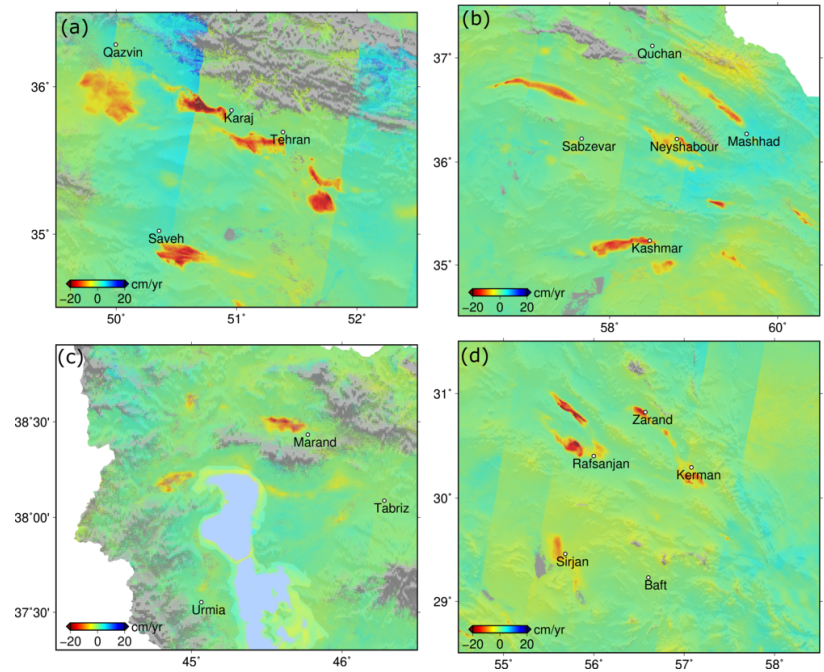

Figure 4. close up views of subsidence areas indicated by dashed lines in Figure 3

irrigated area (Figure 4-b). Mashhad, the second most populated city of Iran, is experiencing a subsidence rate larger than $17 \mathrm{~cm} /$ year.

The third hotspot of subsidence is in the northwest of Iran (Figure 4-c). Several agricultural areas in this region show signs of groundwater stress. In this area, Lake Urmia, once one of the largest salt lakes globally, has been shrinking in the past decades. Parlay because of lowering of groundwater and partly because of damming the rivers that used to flow into the lake, shrinkage of the Lake Urmia is another indicator of water stress in the region (Nikraftar et al., 2021).

The last hotspot of subsidence (Figure 4-d) is located in the southeast of the country where Rafsanjan, Iran's center of Pistachio plantation, is located. Land subsidence in this area exceeds $20 \mathrm{~cm} /$ year at several locations. In various regions near Rafsanjan, signs of inelastic deformation, such as cracks and earth fissures, have been reported in recent years (Motagh et al., 2017).

\subsection{High-resolution analysis of subsidence in Tehran and Mashhad}

After identifying subsidence zones, we monitor them at the highest possible resolution to accurately estimate land subsidence's spatial and temporal behavior at civil infrastructure. Here, we show examples of linear infrastructure affected by surface deformation in Tehran and Mashhad. We first analyze the InSAR time series for six years between 2014 and 2020. Then, we extract the results in a $250-\mathrm{m}$ buffer distance around railways and major roads and highways to analyze the subsidence affecting them.

Figure 5-a illustrates the average subsidence rate affecting national railways and commuter metro lines in Greater Tehran. Several sections of railways in Tehran are affected by land subsidence, namely the Maleki-Aprin section of the national railway with a subsidence rate higher than $15 \mathrm{~cm} /$ year and a section of Tehran-Qom railway with approximately $12 \mathrm{~cm} /$ year of subsidence. Figure 5-b shows a profile of subsidence rate along Line 3, which is is the most severely affected metro line of Tehran. The subsidence rate increases towards the southwest of this line and reaches approximately $7 \mathrm{~cm} /$ year at its peak at Azadegan station. 

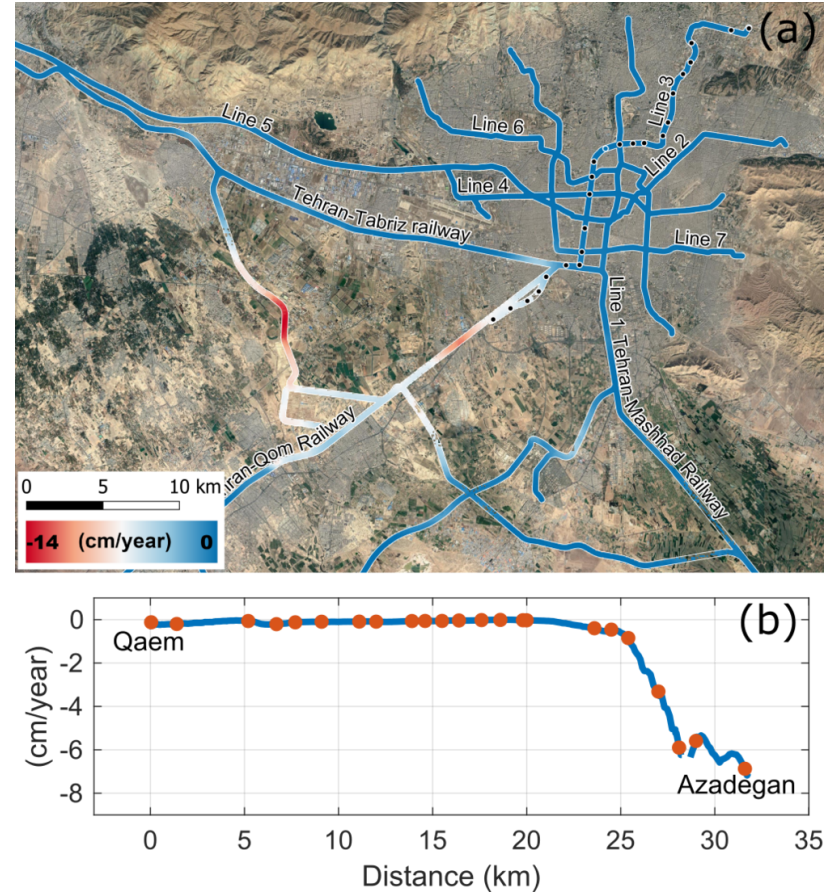

Figure 5. High-resolution analysis of subsidence for monitoring railways and metro lines in Tehran. (a) average rate of subsidence along railways and metro lines. Black circles indicate stations along metro line 3. (b) profile of displacement rate along metro line 3 from Qaem station in the northeast to

Azadegan station in the southwest. Circles indicate metro stations. Background imagery for (a) Google Earth Landsat/Copernicus, Map data @2021

Figure 6-a shows the subsidence rate along highways and major roads in Tehran. Several roads located in the agricultural area to the southwest of Tehran are affected by land subsidence. The highest rate (approximately $18 \mathrm{~cm} /$ year) is near the intersection of Tehran-Saveh freeway and Ahmadabad-Mostofi. Figure 6$b$ illustrates an example time series of subsidence for a point at this intersection. The time series indicates an ongoing longterm subsidence without significant change in the trend during the past six years.

Figure 7 exhibits the subsidence rate along railways and metro lines in Mashhad. Parts of the Mashhad-Tehran railway undergo land subsidence as large as $5 \mathrm{~cm} /$ year. Figure 7-b shows a profile along this railway. Mashhad Metro Line 2 is also affected by land subsidence as significant as $2 \mathrm{~cm} /$ year. The displacement along this Metro Line is shown in figure 7-c.

Figure 8 shows how freeways and major roads in Mashhad are affected by land subsidence. Several parts of the roads in the agricultural area to the northwest of Mashhad are located in subsidence areas with a peak exceeding $15 \mathrm{~cm} /$ year. An example time series at the intersection of Mashhad-Quchan road and the northern beltway road is shown in figure 8-b. The time series exhibits a clear declining trend during the past six years.

\section{DISCUSSION AND CONCLUSION}

Using an enormous dataset of Sentinel-1, we performed a largescale InSAR analysis to quantify land subsidence areas across Iran. One of the main challenges in large-scale InSAR is atmospheric phase delay that can reach several centimeters in
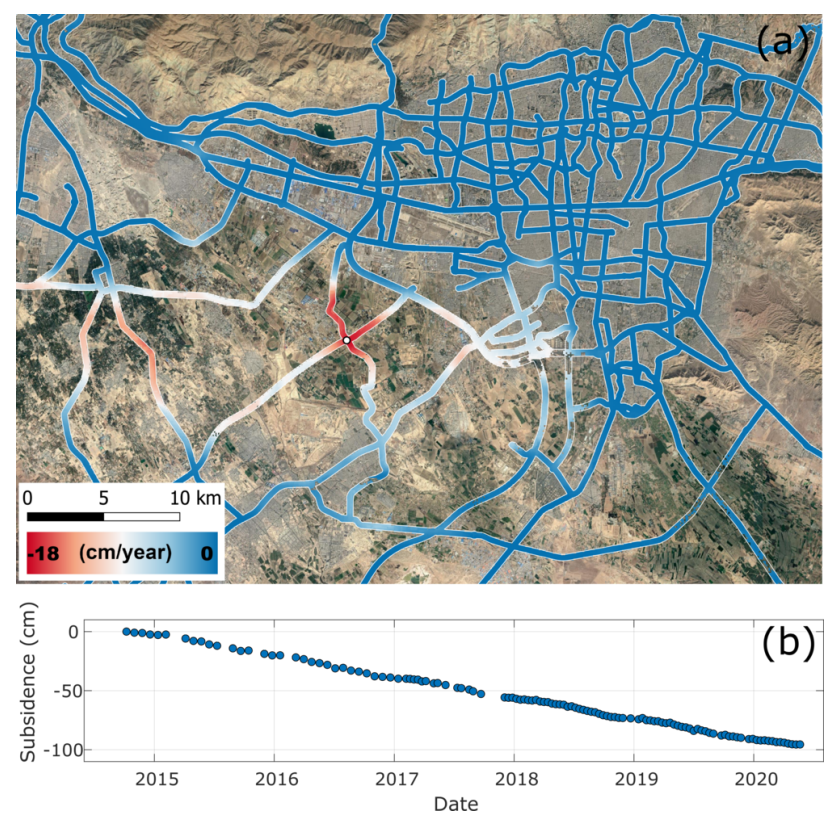

Figure 6. High-resolution analysis of subsidence for monitoring roads and highways in Tehran. (a) average rate of subsidence along major roads and highways. (b) Time series of subsidence for a point, at the intersection of Tehran-Saveh freeway and Ahmadabad-Mostofi road, indicated by white circle in (a). Background imagery for (a) Google Earth Landsat/Copernicus, Map data $\odot 2021$

individual interferograms (Haghshenas Haghighi and Motagh, 2017). Although we employ GACOS correction on the interferograms, there are remaining of atmospheric phase delay visible in the average velocity. This effect is particularly evident between neighboring tracks of InSAR. Nevertheless, it is possible to identify localized subsidence zones in the velocity map. More advanced tropospheric correction methods can improve the identification of subsidence areas (Bekaert et al., 2015).

To validate our subsidence results, we compare our results with those of several subsidence areas identified by previous studies in different parts of Iran (Motagh et al., 2007, Dehghani et al., 2009, Motagh et al., 2008, Haghshenas Haghighi and Motagh, 2019, Babaee et al., 2020). The extent and magnitude of subsidence are to a high degree in agreement. This, on the one hand, confirms the quality of our results. On the other hand, it indicates that, in different basins, groundwater remedial actions either have not been implemented or were not successful in reducing the groundwater stress.

Our country-wide analysis of Sentinel-1 data allowed us to identify more than 100 subsidence zones across Iran with subsidence rates higher than $2 \mathrm{~cm} / \mathrm{year}$. This shows that land subsidence is a widespread problem across Iran. In general, subsidence zones are highly correlated with agricultural areas where a large portion of extracted groundwater is consumed, but it is not limited to farming lands. Many urban areas and infrastructure are also affected by land subsidence. For example, approximately $10 \%$ of Tehran's urban area is undergoing land subsidence.

To address groundwater sustainability, effective water management is required (Vaux, 2011, Elshall et al., 2020). A nationwide medium resolution $(100 \mathrm{~m})$ map of subsidence can help 

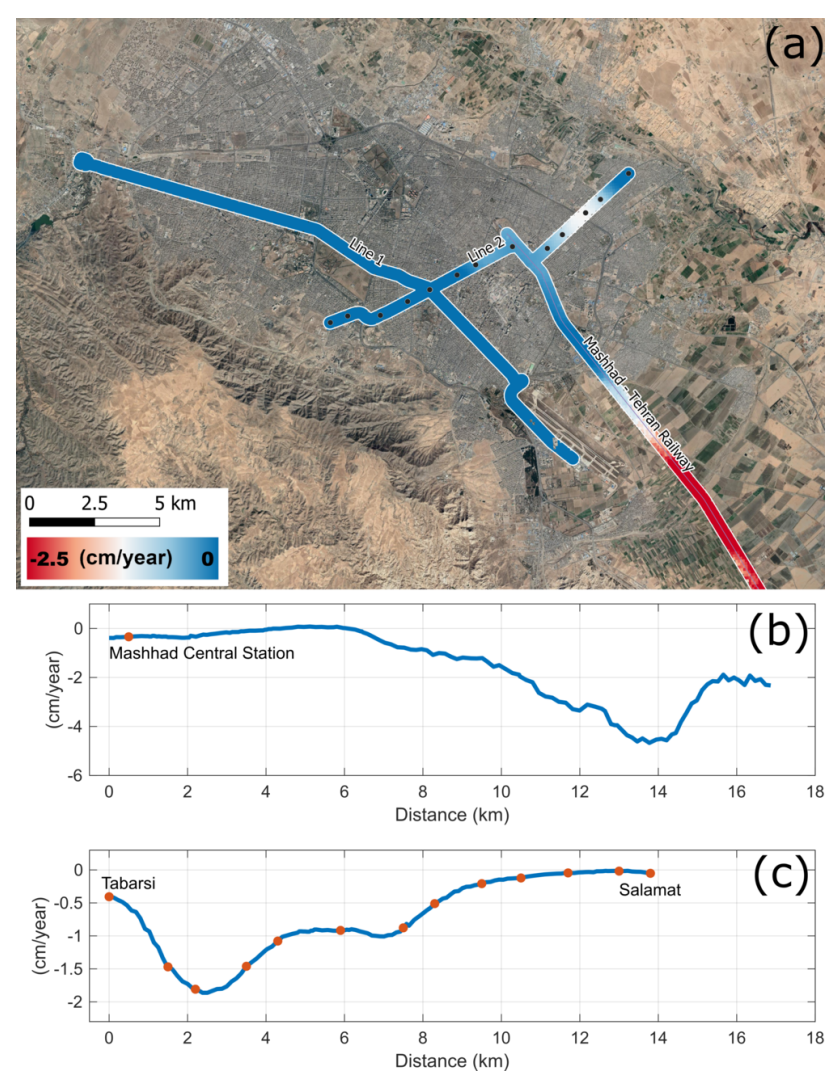

Figure 7. High-resolution analysis of subsidence for monitoring railways and metro lines in Mashhad. (a) average rate of subsidence along railways and metro lines. Black circles indicate stations along metro line 2. (b) profile of displacement rate along metro line 2 from Tabarsi station in the northeast to Salamat station in the southwest. Circles indicate metro stations along this line. (c) profile of displacement rate along

Mashhad-Tehran Railway. The circle indicates Mashhad Central Station. Background imagery for (a) Google Earth Landsat/Copernicus, Map data (2021

decision-makers develop and implement such effective groundwater policies (Madani, 2014, AghaKouchak et al., 2015, Naderi et al., 2021). A 20-year lifetime of Sentinel-1 will allow a frequent update of nationwide subsidence maps in the future, which can be used to verify whether current water management strategies will have effectively reduced groundwater stress.

Our results show great potential for similar large-scale analysis to be extended to other semi-arid and arid areas where water resources are limited and groundwater depletion is a significant issue. Such products over extensive regions can provide valuable information that can be of great interest to businesses, decision-makers, and local communities.

Land subsidence can pose a significant hazard to communities and civil infrastructure. For subsidence zones identified through a medium resolution subsidence mapping, we performed detailed InSAR analysis. The analysis at the highest resolution allowed a detailed monitoring of infrastructure. Our study showed several parts of roads and railways in Tehran and Mashhad are subject to significant subsidence that might threaten their health in the near future.

Such a detailed analysis of deformation is a practical tool for monitoring and managing the health of the civil infrastructure.
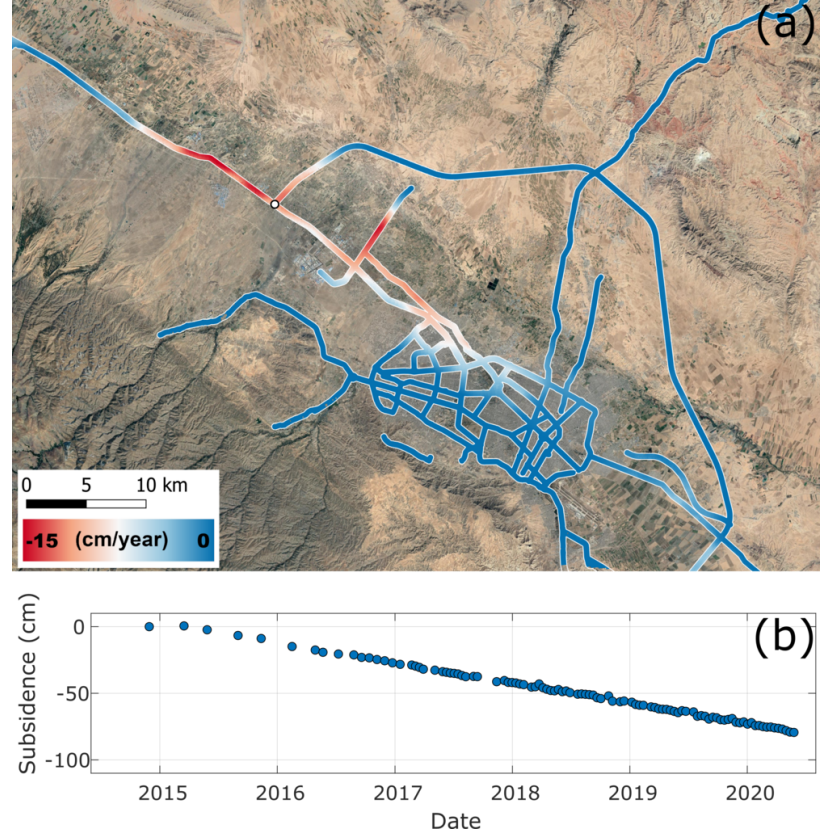

Figure 8. High-resolution analysis of subsidence for monitoring roads and highways in Mashhad. (a) average rate of subsidence along major roads and highways. (b) Time series of subsidence for a point, at the intersection of Mashhad northern freeway and Quchan road, indicated by white circle in (a). Background imagery for (a) Google Earth Landsat/Copernicus, Map data (c)2021

A 6 to 12 day acquisition interval of new Sentinel-1 data allows near real-time monitoring of infrastructure. The results also spot zones of infrastructural deformation that might need to be further investigated. Such zones can be carefully monitored by field equipment or high-resolution SAR sensors such as TerraSAR-X and COSMO-SkyMed.

\section{ACKNOWLEDGEMENTS}

Original SAR data used in this study are Copernicus Sentinel data, processed by ESA. Parts of Map data in Figure 5-8 are copyrighted OpenStreetMap contributors and available from https://www.openstreetmap.org. Some maps were generated using The Generic Mapping Tools (Wessel et al., 2019). Other maps were created using the Free and Open Source QGIS.

\section{REFERENCES}

AghaKouchak, A., Norouzi, H., Madani, K., Mirchi, A., Azarderakhsh, M., Nazemi, A., Nasrollahi, N., Farahmand, A., Mehran, A., Hasanzadeh, E., 2015. Aral Sea syndrome desiccates Lake Urmia: Call for action. Journal of Great Lakes Research, 41(1), 307-311.

Alcamo, J., Döll, P., Henrichs, T., Kaspar, F., Lehner, B., Rösch, T., Siebert, S., 2003. Development and testing of the WaterGAP 2 global model of water use and availability. Hydrological Sciences Journal, 48(3), 317-337.

Alley, W. M., Clark, B. R., Ely, D. M., Faunt, C. C., 2018. Groundwater Development Stress: Global-Scale Indices Compared to Regional Modeling. Groundwater, 56(2), 266-275. 
Amelung, F., Galloway, D. L., Bell, J. W., Zebker, H. A., Laczniak, R. J., 1999. Sensing the ups and downs of Las Vegas: InSAR reveals structural control of land subsidence and aquifer-system deformation. Geology, 27(6), 483-486.

Ashraf, B., AghaKouchak, A., Alizadeh, A., Baygi, M. M., Moftakhari, H. R., Mirchi, A., Anjileli, H., Madani, K., 2017. Quantifying anthropogenic stress on groundwater resources. Scientific reports, 7(1), 1-9.

Babaee, S., Mousavi, Z., Masoumi, Z., Malekshah, A. H., Roostaei, M., Aflaki, M., 2020. Land subsidence from interferometric SAR and groundwater patterns in the Qazvin plain, Iran. International Journal of Remote Sensing, 41(12), 47804798 .

Bekaert, D., Walters, R., Wright, T., Hooper, A., Parker, D., 2015. Statistical comparison of InSAR tropospheric correction techniques. Remote Sensing of Environment, 170, 40-47.

Berardino, P., Fornaro, G., Lanari, R., Sansosti, E., 2002. A new algorithm for surface deformation monitoring based on small baseline differential SAR interferograms. IEEE Transactions on Geoscience and Remote Sensing, 40(11), 2375-2383.

Castellazzi, P., Arroyo-Domínguez, N., Martel, R., Calderhead, A. I., Normand, J. C., Gárfias, J., Rivera, A., 2016. Land subsidence in major cities of Central Mexico: Interpreting InSARderived land subsidence mapping with hydrogeological data. International Journal of Applied Earth Observation and Geoinformation, 47, 102-111.

Chaussard, E., Wdowinski, S., Cabral-Cano, E., Amelung, F., 2014. Land subsidence in central Mexico detected by ALOS InSAR time-series. Remote Sensing of Environment, 140, 94106.

Cigna, F., Osmanoğlu, B., Cabral-Cano, E., Dixon, T. H., Ávila Olivera, J. A., Garduño-Monroy, V. H., DeMets, C., Wdowinski, S., 2012. Monitoring land subsidence and its induced geological hazard with Synthetic Aperture Radar Interferometry: A case study in Morelia, Mexico. Remote Sensing of Environment, 117, 146-161. Remote Sensing of Urban Environments.

Dalin, C., Wada, Y., Kastner, T., Puma, M. J., 2017. Groundwater depletion embedded in international food trade. Nature, 543(7647), 700-704.

Dehghani, M., Valadan Zoej, M. J., Entezam, I., Mansourian, A., Saatchi, S., 2009. InSAR monitoring of progressive land subsidence in Neyshabour, northeast Iran. Geophysical Journal International, 178(1), 47-56.

Elshall, A. S., Arik, A. D., El-Kadi, A. I., Pierce, S., Ye, M., Burnett, K. M., Wada, C. A., Bremer, L. L., Chun, G., 2020. Groundwater sustainability: A review of the interactions between science and policy. Environmental Research Letters, 15(9), 093004

Farr, T. G., Kobrick, M., 2000. Shuttle Radar Topography Mission produces a wealth of data. Eos, Transactions American Geophysical Union, 81(48), 583-585.

Ferretti, A., Fumagalli, A., Novali, F., Prati, C., Rocca, F. Rucci, A., 2011. A New Algorithm for Processing Interferometric Data-Stacks: SqueeSAR. IEEE Transactions on Geoscience and Remote Sensing, 49(9), 3460-3470.
Galloway, D. L., Burbey, T. J., 2011. Regional land subsidence accompanying groundwater extraction. Hydrogeology Journal, 19(8), 1459-1486.

Haghshenas Haghighi, M., Motagh, M., 2017. Sentinel-1 InSAR over Germany: Large-scale interferometry, atmospheric effects, and ground deformation mapping. ZfV: Zeitschrift für Geodäsie, Geoinformation und Landmanagement, 2017(4), 245-256.

Haghshenas Haghighi, M., Motagh, M., 2019. Ground surface response to continuous compaction of aquifer system in Tehran, Iran: Results from a long-term multi-sensor InSAR analysis. Remote Sensing of Environment, 221, 534-550.

Hooper, A., 2008. A multi-temporal InSAR method incorporating both persistent scatterer and small baseline approaches. Geophysical Research Letters, 35(16).

Hooper, A., Segall, P., Zebker, H., 2007. Persistent scatterer interferometric synthetic aperture radar for crustal deformation analysis, with application to Volcán Alcedo, Galápagos. Journal of Geophysical Research: Solid Earth, 112(B7).

Madani, K., 2014. Water management in Iran: what is causing the looming crisis? Journal of environmental studies and sciences, 4(4), 315-328.

Madani, K., AghaKouchak, A., Mirchi, A., 2016. Iran's Socioeconomic Drought: Challenges of a Water-Bankrupt Nation. Iranian Studies, 49(6), 997-1016.

Motagh, M., Djamour, Y., Walter, T. R., Wetzel, H.-U., Zschau, J., Arabi, S., 2007. Land subsidence in Mashhad Valley, northeast Iran: Results from InSAR, levelling and GPS. Geophysical Journal International, 168(2), 518-526.

Motagh, M., Shamshiri, R., Haghshenas Haghighi, M., Wetzel, H.-U., Akbari, B., Nahavandchi, H., Roessner, S., Arabi, S., 2017. Quantifying groundwater exploitation induced subsidence in the Rafsanjan plain, southeastern Iran, using InSAR time-series and in situ measurements. Engineering Geology, $218,134-151$

Motagh, M., Walter, T. R., Sharifi, M. A., Fielding, E., Schenk, A., Anderssohn, J., Zschau, J., 2008. Land subsidence in Iran caused by widespread water reservoir overexploitation. Geophysical Research Letters, 35(16).

Mousavi, S. M., Shamsai, A., Naggar, M. H. E., Khamehchian, M., 2001. A GPS-based monitoring program of land subsidence due to groundwater withdrawal in Iran. Canadian Journal of Civil Engineering, 28(3), 452-464.

Naderi, M. M., Mirchi, A., Bavani, A. R. M., Goharian, E., Madani, K., 2021. System dynamics simulation of regional water supply and demand using a food-energy-water nexus approach: Application to Qazvin Plain, Iran. Journal of Environmental Management, 280, 111843.

Nikraftar, Z., Parizi, E., Hosseini, S. M., Ataie-Ashtiani, B., 2021. Lake Urmia restoration success story: A natural trend or a planned remedy? Journal of Great Lakes Research.

Richey, A. S., Thomas, B. F., Lo, M.-H., Reager, J. T., Famiglietti, J. S., Voss, K., Swenson, S., Rodell, M., 2015. Quantifying renewable groundwater stress with GRACE. Water Resources Research, 51(7), 5217-5238. 
Vaux, H., 2011. Groundwater under stress: the importance of management. Environmental Earth Sciences, 62(1), 19-23.

Wada, Y., van Beek, L. P. H., Bierkens, M. F. P., 2011. Modelling global water stress of the recent past: on the relative importance of trends in water demand and climate variability. Hydrology and Earth System Sciences, 15(12), 3785-3808.

Wang, G., Soler, T., 2015. Measuring Land Subsidence Using GPS: Ellipsoid Height versus Orthometric Height. Journal of Surveying Engineering, 141(2), 05014004.

Wessel, P., Luis, J. F., Uieda, L., Scharroo, R., Wobbe, F., Smith, W. H. F., Tian, D., 2019. The Generic Mapping Tools Version 6. Geochemistry, Geophysics, Geosystems, 20(11), $5556-5564$.

Yagüe-Martínez, N., Prats-Iraola, P., Rodríguez González, F., Brcic, R., Shau, R., Geudtner, D., Eineder, M., Bamler, R., 2016. Interferometric Processing of Sentinel-1 TOPS Data. IEEE Transactions on Geoscience and Remote Sensing, 54(4), 2220-2234.

Yu, C., Li, Z., Penna, N. T., Crippa, P., 2018. Generic Atmospheric Correction Model for Interferometric Synthetic Aperture Radar Observations. Journal of Geophysical Research: Solid Earth, 123(10), 9202-9222. 